\title{
ISOLATED EYELID TUBERCULOSIS
}

\author{
Ashok Kumar Narsani, Shafi Muhammad Jatoi and Syed Asher Dabir
}

\begin{abstract}
We report a case of a seventy years old lady of poor socioeconomic background who presented with painless swelling of the right upper lid since one year. No other local or systemic features were associated. An incisional biopsy was performed under local anaesthesia. Histopathological examination revealed epitheloid granuloma with Langerhan's giant cells suggestive of tuberculosis of lid skin. The clinical events and pathological findings were suggestive of Mycobacterium tuberculosis as the cause of infection. After diagnosis, the patient was referred to physician for anti-tuberculosis therapy. The eyelid swelling resolved gradually and was completely normal after 9 months of chemotherapy.
\end{abstract}

KEY WORDS: Tuberculosis. Eye. Biopsy. Management.

\section{INTRODUCTION}

"Ocular tuberculosis" encompasses any infection by Mycobacterium tuberculosis or one of three related mycobacteria species (sp. bovis, africanum and microti), in, on, or around the eye. ${ }^{1}$ Ocular tuberculosis may be primary or secondary in nature. In primary ocular tuberculosis, there are no other systemic lesions, whereas secondary ocular tuberculosis is defined as an infection resulting from contagious spread from adjacent structure or by hematogenous spread. ${ }^{2}$ Eyelid involvement is almost always secondary to orbital involvement and often seen in the form of drainage sinus. Eyelid scarring resulting in the cicatrical ectropion and lagophthalmos or adhesion of eyelid structures to the underlying orbital bones, isolated involvement of the eyelids without orbital or systemic involvement is extremely uncommon. ${ }^{3,4}$

\section{CASE REPORT}

A seventy years old lady presented with one year history of progressive swelling in her right upper eyelid at our department (Figure I). Patient did not have fever, respiratory symptoms or any history of weight loss. She gave history of removal of such lesion three times in the past. The record of previous treatment showed that patient was managed as a case of Chalazion. The eye examination revealed an endured cold and painless diffuse swelling of the right upper lid mainly on the temporal side associated with mild drooping of upper eyelid. There was no impairment of ocular motility or proptosis. Best corrected visual acuity of both eyes was 6/6, anterior segment was normal, media clear and no any fundus finding was also seen. Patient was advised for X-ray chest which was normal. Routine blood investigations such as TLC, DLC and ESR were also normal. In mantoux test, zone of induration was $08 \mathrm{~mm}$ after 72 hours and sputum for acid fast bacilli was also negative. Incisional biopsy was performed under local anaesthesia (Figure II). Histopathological examination revealed lesion lined by keratinized stratified squamous epithelium with underneath stroma showing granulomatous reaction consisting of epitheloid cells, Langerhan's giant cells with surrounded rim of lymphocytes suggesting of tuberculosis (Figure III). The clinical events and pathological findings were suggestive of Mycobacterium tuberculosis as the cause of isolated eyelid lesion. The patient was put on anti tuberculosis therapy with Isoniazid and Rifampicin for 9 months. When reviewed after 2 months, the lid lesion had resolved dramatically except the skin which looked stretched and shining. Patient was asked to continue anti-tuberculosis therapy for 9 months and full resolution with mild depigmentation was noted at the end of the treatment (Figure IV).

FIGURE I:

\section{RIGHT EYE ISOLATED EYELID TUBERCULOSIS} (BEFORE TREATMENT)

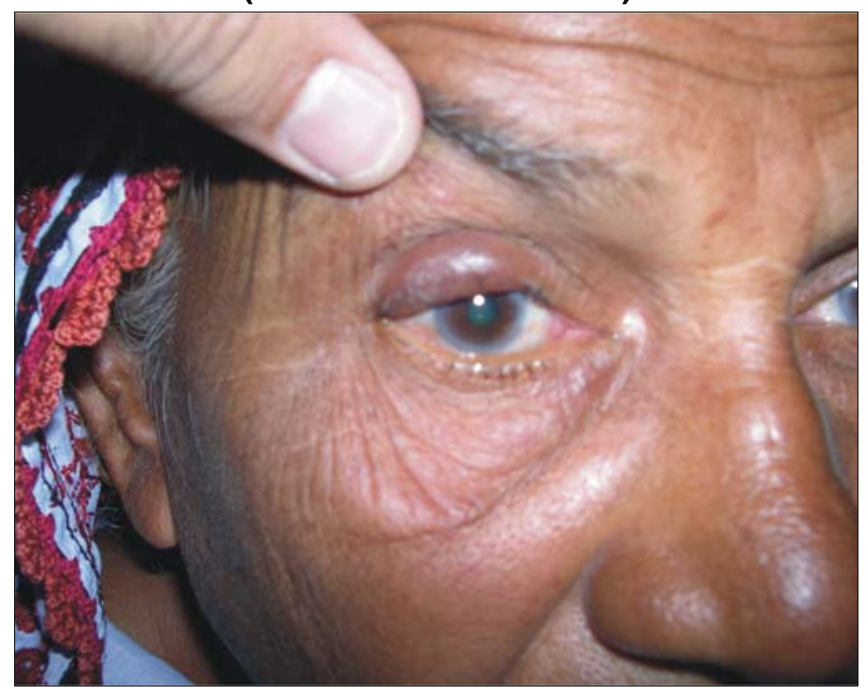


FIGURE II:

BIOPSY SITE OF ISOLATED EYELID TUBERCULOSIS

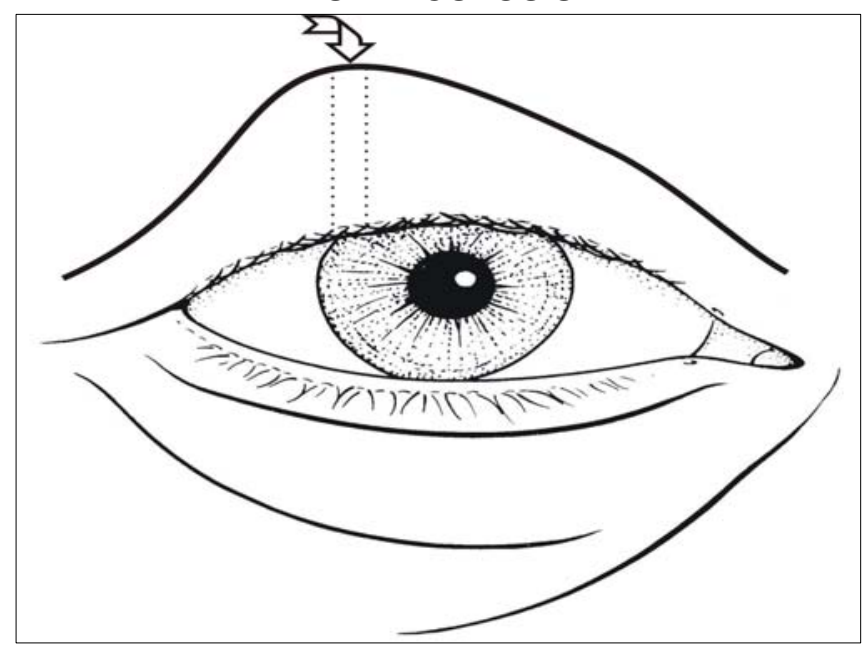

FIGURE III:

HISTOPATHOLOGICAL SLIDE OF ISOLATED EYE LID TUBERCULOSIS

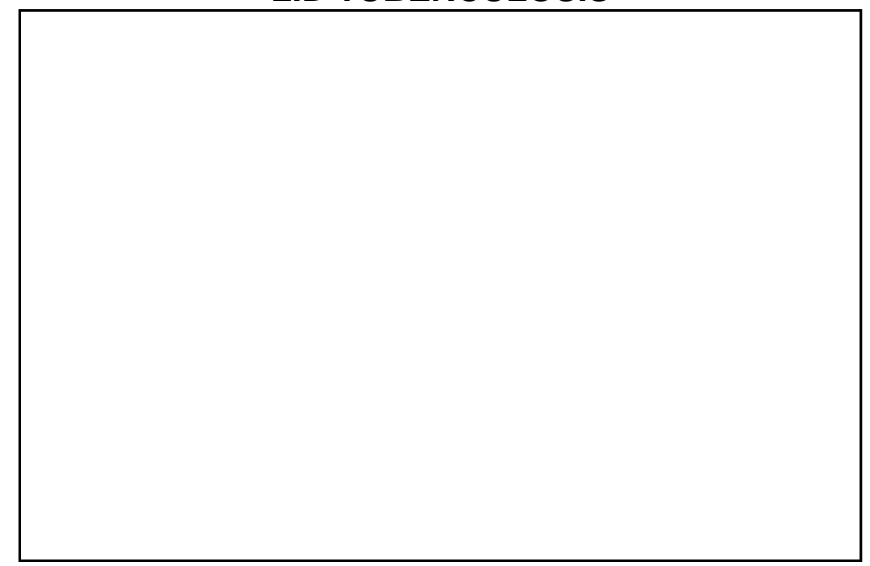

FIGURE IV:

RIGHT EYE ISOLATED EYE LID TUBERCULOSIS (AFTER TREATMENT)

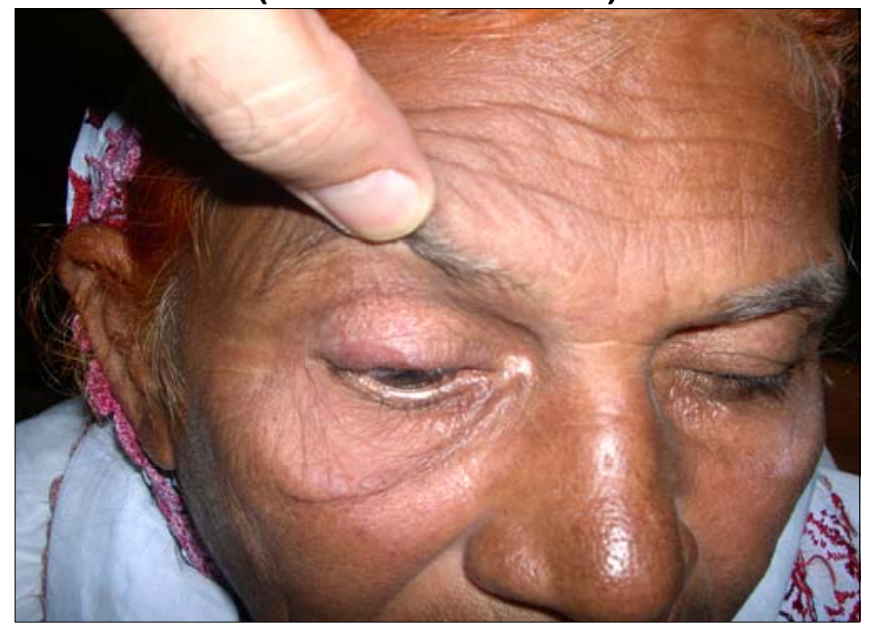

\section{DISCUSSION}

Tuberculosis is a major cause of death around the world particularly in developing countries. ${ }^{5}$ This situation is mainly due to the inadequate control of high prevalence of the disease in developing countries and its association with Human Immunodeficiency Virus infection. ${ }^{6}$ The incidence of ophthalmic manifestations in patients known to have systemic tuberculosis is only $1-2 \% .{ }^{7}$ After primary infection, the tubercle bacilli can disseminate hematogenously, giving rise to infection in almost every organ including eye. ${ }^{8}$ Orbital involvement by tuberculosis, even in endemic areas is rare. Orbital infection can occur due to hematogenic spread as well as direct spread from contagious sites (paranasal sinuses, lacrimal glands and the sac). The most common clinical manifestations of orbital tuberculosis are insidious and progressive unilateral proptosis, a cold, painless eyelid swelling, chemosis and conjunctival hyperemia. In some cases, there may be involvement of the ocular movements, and in few cases, loss of visual acuity or visual fields. ${ }^{6,9}$ In this case, patient presented with painless isolated eyelid swelling which is extremely uncommon. On the basis of histopathological report, this patient was considered to have primary ocular tuberculosis. The diagnosis of ocular tuberculosis is complicated by the difficulties associated with ocular sampling for microbiologic evaluation. A presumptive diagnosis is commonly based on the finding of acid fast bacilli during microscopic examination of diagnostic specimen. A definitive diagnosis is dependent on a positive culture of the organism from a diagnostic specimen, which is time consuming. The tuberculin skin test is of limited value, because of its low sensitivity and specificity. Recently, one of the most promising diagnostic technique, the amplification and detection of specific segments of DNA by polymerase chain reaction, was used to diagnose the disease with high sensitivity and specificity. ${ }^{10}$ Moreover, it is especially useful for diagnosing primary ocular tuberculosis because only a small sample is needed and viable cells are not required. ${ }^{2}$ This case was diagnosed on the basis of histopathological findings and on clinical ground with complete resolution of the disease with specific anti-tuberculosis medications. Despite the difficulties in diagnosis, the treatment of tuberculosis is relatively effective and costefficient. $^{2}$ Treatment of ocular tuberculosis is same as for other forms of tuberculosis. ${ }^{8}$ After diagnosis as case of isolated eyelid tuberculosis, the patient was referred to physician for anti-tuberculosis treatment. The lesion totally resolved after anti-tuberculosis treatment for 9 months. 


\section{CONCLUSION}

It is concluded that the tuberculosis should be considered in the differential diagnosis of chronic painless eyelid swelling and histopathological report may be obtained for every eyelid lesion after excision.

\section{REFERENCES}

1. Varma D, Anand S, Reddy AR, Das A, Watson JP, Currie DC, et al. Tuberculosis: an underdiagnosed aetiological agent in uveitis with an effective treatment. Eye. 2006;20(9):1068-73.

2. Sheu SJ, Shyu JS, Chen LM, Chen YY, Chirn SC, Wang JS. Ocular manifestations of tuberculosis. Ophthalmology. 2001;108(9):1580-5.

3. Helm CJ, Holland GN. Ocular tuberculosis. Surv Ophthalmol. 1993; 38(3): 229-56.

4. D' Souza P, Garg R, Dhaliwal RS, Jain R, Jain M. Orbital tuberculosis. Int Ophthalmol. 1994;18 (3):149-52.
5. Flynn JL, Chan J. Immunology of tuberculosis. Annu Rev Immunol. 2001;19: 93-129.

6. Oliveira BF, Takay FC, Shida TM, Santo RM, Souza AC, Matayoshi S. Orbital tuberculosis diagnosed by immunohistochemistry: case reports. Rev Inst Med Trop Sao Paulo. 2004; 46(5):291-4.

7. Demirci $H$, Shields $C L$, Shields JA, Eagle RC. Ocular tuberculosis masquerading as ocular tumors. Surv Ophthalmol. 2004; 49(1):78-89.

8. Lynn WA, Lightman S. The eye in systemic infection. Lancet 2004; 364(9443):1439-50.

9. Davies PD. The world-wide increase in tuberculosis: how demographic changes, HIV infection and increasing numbers in poverty are increasing tuberculosis. Ann Med. 2003; 35 (4):235-243.

10. Kotake S, Kimura K, Yoshikawa K, Sasamoto $Y$, Matsuda A, Nishikawa T, et al. Polymerase chain reaction for the detection of Mycobacterium tuberculosis in ocular tuberculosis (case report). Am J Ophthalmol. 1994;117(6): 805-6.

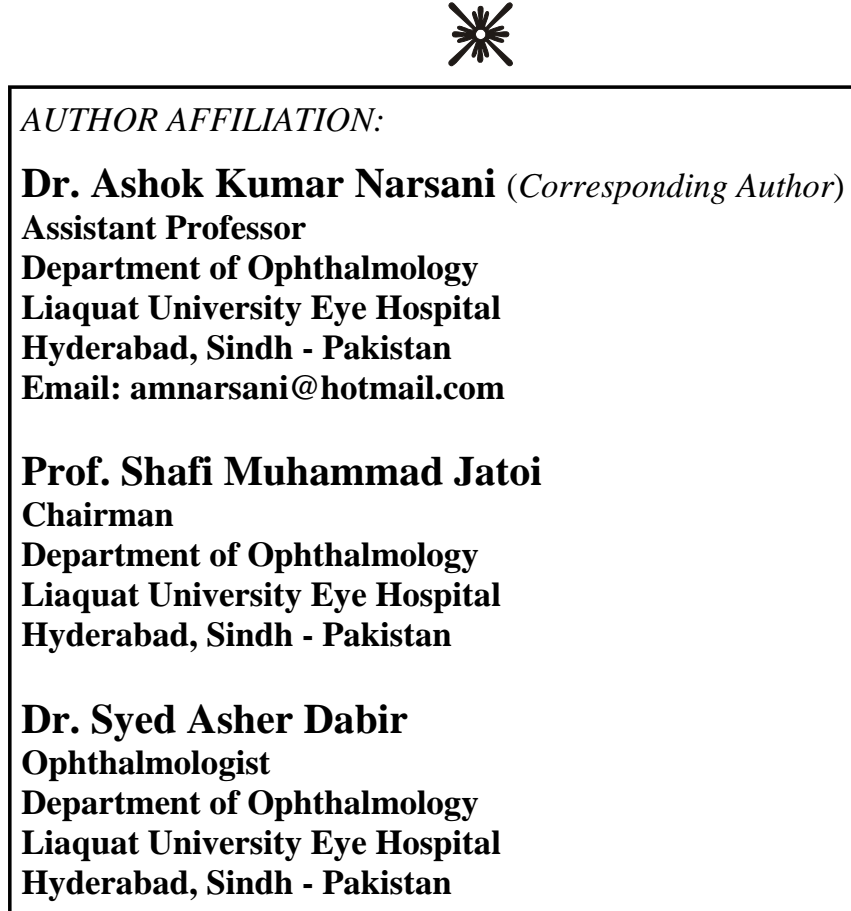

